\title{
Precarização do Trabalho e Risco de Acidentes na construção civil: um estudo com base na Análise Coletiva do Trabalho (ACT)'
}

\author{
Work Precariousness and Risk of Accidents in Civil
}

Construction: A study based on the Collective Work Analysis

\author{
Mara Alice Batista Conti Takahashi \\ Doutora em Saúde Coletiva, Socióloga do Centro de Referência em \\ Saúde do Trabalhador de Piracicaba (CEREST-Piracicaba) \\ Endereço: Rua São Francisco de Assis, 983, Centro, CEP 13400-590, \\ Piracicaba, SP, Brasil. \\ E-mail: maraconti_takळyahoo.com.br \\ Reginalice Cera da Silva \\ Mestre em Saúde Pública, Educadora em Saúde do Centro de \\ Referência em Saúde do Trabalhador de Piracicaba (CEREST- \\ Piracicaba), Docente da Faculdade de Ciências da Saúde - Curso \\ de Fonoaudiologia, Universidade Metodista de Piracicaba. \\ Endereço: Rodovia do açúcar Km 156. CEP 13400-911, Piracicaba, \\ SP, Brasil. \\ E-mail: realiceı®yahoo.com.br

\section{Luiz Eduardo Cobra Lacorte} \\ Mestre em Saúde Pública, Especialista em Saúde do Trabalhador, \\ Psicólogo do Centro de Referência em Saúde do Trabalhador de \\ Piracicaba (CEREST-Piracicaba). \\ Endereço: Rua São Francisco de Assis, 983, Centro, CEP 13400- 590, \\ Piracicaba, SP Brasil. \\ E-mail: pitepiraळyahoo.com.br
}

\section{Gislaine Cecília de Oliveira Ceverny}

Doutora em Biologia Patologia Buço Dental. Docente da Faculdade de Ciências da Saúde - Curso de Fisioterapia, Universidade Metodista de Piracicaba.

Endereço: Rodovia do açúcar Km 156. CEP 13400-911, Piracicaba, SP, Brasil.

E-mail: gicervenyळyahoo.com.br

\section{Rodolfo Andrade Gouveia Vilela}

Doutor em Saúde Coletiva, Docente da Faculdade de Saúde Pública, Universidade de São Paulo.

Endereço: Av Dr. Arnaldo no 715, Cerqueira Cesar, CEP 01246-904, São Paulo, SP, Brasil.

E-mail: ravilelaœusp.br

I Pesquisa financiada pela FAPESP Processo no 06/51684-3.

\section{Resumo}

Este artigo descreve a atividade e a percepção dos trabalhadores da construção civil sobre os riscos e a carga de trabalho. 0 estudo, com base na Análise Coletiva de Trabalho (ACT), é parte de pesquisa em políticas públicas para aprimoramento do Sistema de Vigilância em Acidentes de Trabalho (SIVAT) de Piracicaba-SP. Priorizou-se a construção civil pela magnitude epidemiológica de ocorrência de acidentes de trabalho e a baixa eficácia das ações tradicionais de vigilância pelas características de informalidade, terceirização e rotatividade do setor. Os trabalhadores revelaram elevada percepção dos riscos de acidentes e que as medidas de segurança dificultam ou impedem a realização do trabalho. Os achados questionam a eficácia dos treinamentos para adesão às medidas de segurança e evidenciam a necessidade de uma pedagogia transformadora nas ações de promoção da saúde e prevenção dos acidentes de trabalho.

Palavras-chave: Acidentes de trabalho na construção civil; Análise Coletiva do Trabalho; Prevenção e Promoção da Saúde. 


\section{Abstract}

This paper aims to describe the construction workers' activities, as well as their perceptions about risks and workload. The study, based on the Collective Work Analysis, is part of a broader public policies project for the improvement of SIVAT (Surveillance System of Work Accidents) - in the city of Piracicaba (Southeastern Brazil). Civil construction was prioritized given the epidemiological magnitude of the occurrence of work accidents and the limited efficacy of traditional surveillance initiatives in this sector due to informal employment practices, outsourcing, high staff turnover, etc. The workers have a high level of awareness concerning the risk of accidents, but they believe that the main preventive measures hinder or even make it impossible for them to carry out the tasks. Our findings question the efficacy of traditional training for adherence to safety practices, thus highlighting the need for a transformative pedagogy for preventive practices and the health promotion of workers.

Keywords: Work Accidents in civil Construction; Collective Work Analysis; Health Promotion and Prevention.

\section{Introdução}

Historicamente, no Brasil, a construção civil representa o setor de maior absorção de mão de obra, dada a abrangência de sua variada oferta de trabalho, sem muitas restrições para o recrutamento. Dados do Departamento Intersindical de Estatística e Estudos Socioeconômicos (Dieese, 2001) referem que o setor empregava quatro milhões e setecentos mil trabalhadores, $80 \%$ desse contingente na informalidade. A construção civil constitui-se, portanto, em um setor produtivo importante no cenário econômico brasileiro, responsável na época por 10,3\% do Produto Interno Bruto. Dados recentes (Dieese, 2011) mostram crescimento no setor que totalizam cinco milhões e oitocentos mil trabalhadores, o que representa $6,5 \%$ da população ocupada.

A magnitude da ocorrência dos acidentes de trabalho (AT) e doenças ocupacionais (DO) na construção civil no período de 2003 a 2005, em que o Instituto Nacional do Seguro Social registrou 83.842 casos (CNAE 4511 a 4560), destaca este setor como um dos ramos produtivos mais perigosos (Ministério da Previdência Social, 2007).

Santana e Oliveira (2004) afirmam que os trabalhadores da construção civil mostram estágios mais avançados de precarização do trabalho que os demais trabalhadores, evidenciados pela maior proporção de trabalhadores informais, sem contrato assinado em carteira, bem como trabalhadores que subsistem por meio de "bicos".

Dados do Banco Mundial indicam que 50\% da mão de obra brasileira urbana está no mercado informal da economia, no qual além da baixa remuneração, os trabalhadores são privados dos benefícios da Previdência Social, sem garantia de suporte financeiro em casos de doenças e acidentes e sem aposentadoria remunerada. Outro lado da precarização no trabalho informal é a ausência de sindicalização e a reconhecida negligência dos empregadores quanto às medidas de proteção, de segurança e saúde, uma vez que estes trabalhadores encontram-se à margem do controle do Estado (Iriart e col., 2008).

Segundo Tomás (2000, 2001) o trabalho é considerado precário quando: realizado de forma descontínua, submetido à arbitrariedade empresarial 
sem limites, com risco de perda elevada, tendo a incerteza e a temporalidade como norma; ausência de controle do trabalho tanto na dimensão individual quanto coletiva; péssimas condições laborais, sem direitos trabalhistas e benefícios previdenciários, alta discriminação, rotatividade elevada, exploração e segregação e finalmente salários baixos, pouca possibilidade de ascensão funcional, formação educacional escassa ou nula, com antecedentes de trabalho infantil.

Oliveira (2004) traz uma descrição precisa do panorama de incremento da precarização do trabalho na construção civil, no Brasil. Segundo o autor, as construtoras, com o objetivo de reduzir o custo do trabalho e maximizar a eficácia produtiva, implantaram medidas de descentralização de um número crescente de tarefas, em condições precárias e menos protegidas, criando em cascata um segundo mercado de trabalho sem direitos trabalhistas e previdenciários, em que os riscos de acidentes de trabalho e doenças profissionais tornam-se ainda maiores para os terceirizados (formais), para os trabalhadores informais e para os biscateiros.

No canteiro de obras, diferentes empresas atuam em conjunto. As empreiteiras realizam a subcontratação de pequenas empresas ou mão de obra direta, à margem da legislação trabalhista. A construtora principal assina o projeto e torna-se uma mera gerenciadora do empreendimento. A rotatividade de mão de obra é proposital: no final de cada etapa da construção, há uma dispensa coletiva de trabalhadores que voltam a ser contratados em etapas posteriores (Oliveira, 2004).

O desenvolvimento de sistemas locais de informação para acompanhar os impactos do trabalho na saúde constitui-se em um dos grandes desafios da Rede Nacional de Saúde do Trabalhador (RENAST) dentro do SUS (Sistema Único de Saúde). Tradicionalmente, os dados sobre acidentes de trabalho, no Brasil, eram exclusividade do sistema da Previdência Social, que cobre apenas a população formal vinculada ao Seguro do Acidente de Trabalho (SAT), que apresenta reconhecida subnotificação dos acidentes de trabalho, da ordem de $90 \%$, e muitas dificuldades em socializar as informações, por estar comprometido, segundo a alegação institucional, com o sigilo fiscal devido a sua natureza arrecadatória.

Em Piracicaba (SP), o Sistema de Vigilância em Acidentes de Trabalho (SIVAT), está em operação contínua desde 2003 e tem como finalidade colher, registrar, armazenar, consolidar e analisar, de forma sistemática, os dados de acidentes de trabalho ocorridos no município, com trabalhadores do mercado formal e informal.

Este sistema funciona a partir da informação recebida de 21 serviços de saúde que prestam atendimento de urgência e emergência ${ }^{2}$, atuam como provedores dos dados sobre os acidentes de trabalho, uma vez que são unidades de notificação obrigatória ${ }^{3}$, independentemente da existência ou da natureza do vínculo empregatício dos acidentados. A coleta é feita por meio do preenchimento do Relatório de Atendimento ao Acidente do Trabalho (RAAT) pelos funcionários da recepção, enfermagem e médicos atendentes das unidades-sentinelas. Estes são encaminhados diariamente ao Centro de Referência em Saúde do Trabalhador de Piracicaba (CEREST-Piracicaba) que atua como uma central de convergência das informações, responsabilizandose pela digitação dos dados em um programa informatizado, especialmente desenhado para o seu armazenamento e gerenciamento.

Dados consolidados do SIVAT-Piracicaba, referentes ao período de o1 de janeiro de 2004 a 15 de setembro de 2009, apontaram que, dentre 37.124 acidentes de trabalho notificados no município de Piracicaba, 3.158 (8,5\%) ocorreram na construção civil.

As características de organização do trabalho do setor - precarização, terceirização, fragilidade dos vínculos empregatícios, alta rotatividade, baixos níveis de escolaridade e baixos salários - apresentamse como obstáculos às ações de vigilância em saúde do trabalhador.

\footnotetext{
2 São eles, cinco Prontos-Socorros, três hospitais privados, um hospital filantrópico conveniado com a Rede SUS e doze ambulatórios médicos de empresas de grande porte.

3 Decreto-Lei nº 9.951 "Dispõe sobre a notificação obrigatória dos acidentes de trabalho no município de Piracicaba-SP" Do de 12/08/2002.
} 
As ações tradicionais de vigilância resumem-se à verificação dos riscos, tendo como referência o trabalho prescrito, "o jeito certo de fazer", ou seja, o procedimento normatizado, preferencialmente pelas Normas Regulamentadoras (NR) do Ministério do Trabalho. Desse modo, as ações educativas em Saúde do Trabalhador, advindas desta concepção, voltam-se para o aprendizado de regras de conduta e procedimentos de segurança, o que se mostra pouco eficaz e requer a incorporação de novos metodologias e conteúdos para a formação de agentes multiplicadores de saúde e segurança na construção civil.

Consoante com Assunção e Lima (2003), o entendimento da equipe do CEREST Piracicaba é de que as normas e os procedimentos constituem um modelo "ideal" de trabalho, um modelo "depurado", que se mostra insuficiente para garantir a segurança de um sistema, uma vez que é impossível prever, de antemão, todas as eventualidades do trabalho, a multiplicidade das ocorrências e a proliferação de microdetalhes cuja formalização implicaria num enorme e complexo labirinto de modos operatórios possíveis. Na realidade, como aponta Llory (1999) a aplicação estrita e rigorosa dos procedimentos, das regras formais de trabalho, conduz à paralisia dos sistemas, tendo como exemplo a greve do zelo, que é acionada pelos operadores como forma de realizar a operação padrão, de só seguir o que está no padrão, paralisando a atividade laboral. Para atender à imprevisibilidade do trabalho é necessário, então, repensar as práticas educativas que considerem e incorporem o saber fazer do trabalhador.

Por não partilharem desta compreensão, as ações educativas tradicionais de promoção e educação em Saúde do Trabalhador, voltadas para o aprendizado de regras de conduta e procedimentos de segurança, tem se mostrado pouco eficazes, requerendo a incorporação de novas metodologias e novos conteúdos para a formação de agentes multiplicadores de saúde e segurança na construção civil.

Este entendimento é corroborado por outros autores como Medeiros e Rodrigues (2001) que sugerem a dramatização ou outras propostas didáticas alternativas como estratégias de formação em saúde e segurança na construção civil e outros ramos de atividades, de acordo com a riqueza cultural própria dos trabalhadores a quem se destina o aprendizado.
Criticando as campanhas de segurança, dispostas de forma assustadora e compulsória, os autores lembram Berlinguer e sua proposta dialógica com os trabalhadores para se conhecer as condições de trabalho e detectar as situações ocupacionais nocivas; é preciso saber o que eles sentem, percebem ou relatam como fatores prejudiciais à sua saúde. No entendimento do importante sanitarista italiano "inspecionar a fábrica sem conversar com os trabalhadores é como exercer a clínica com o doente e não ouvir a sua história" (Berlinguer, 1983, apud Medeiros e Rodrigues, 2001, p. 8).

O objetivo deste artigo é descrever a atividade e a percepção dos trabalhadores da construção civil sobre os riscos e a carga de trabalho, captados pelo discurso dos próprios trabalhadores, de modo a produzir subsídios para desenvolvimento de ações de promoção da saúde dos trabalhadores. 0 artigo descreve os resultados de pesquisa realizada no ano de 2008, com trabalhadores da construção civil, no município de Piracicaba-SP, como parte de um projeto de pesquisa em políticas públicas de aprimoramento do Sistema de Vigilância em Acidentes de Trabalho SIVAT - Piracicaba (FAPESP o6/51684-3).

\section{Método e Procedimentos de Pesquisa}

Foi utilizado o método da Análise Coletiva do Trabalho (ACT), proposto por Ferreira (1993), como instrumento para aproximar-se do ponto de vista dos trabalhadores sobre os problemas que os afligem na atividade laboral, a partir da representação que eles têm do próprio trabalho, servindo de base para a intervenção na realidade. Segundo a autora, a ACT "é um método de abordagem dos sentimentos que o trabalho provoca e mobiliza" (Ferreira, 1993, p. 8).

Esse método consiste em formar um grupo de trabalhadores voluntários, sem definição prévia do número mínimo ou máximo de integrantes, que se reúnem fora do local do trabalho, em ambiente identificado pelos trabalhadores como não patronal, na presença de pelo menos dois pesquisadores, com experiência em Análise Ergonômica do Trabalho (AET), que conduzem a reunião com o auxílio de perguntas como: $O$ que fazem no seu trabalho? Por que fazem? E como fazem? 
Contudo, diferente do que preconiza Ferreira, a demanda para esse estudo não partiu dos próprios trabalhadores da construção civil ou do sindicato da categoria, mas surgiu da necessidade do CERESTPiracicaba de intervir na problemática, diante dos resultados consolidados pelo SIVAT, cujo diagnóstico apontava para um número significativo de acidentes de trabalho neste setor, expressando, no entendimento da equipe, o baixo impacto das ações regulatórias tradicionais em Vigilância em Saúde e Segurança no Trabalho.

A estratégia utilizada para acessar os trabalhadores, principalmente os informais, foi envolver o Sindicato dos Trabalhadores nas Indústrias da Construção e do Mobiliário de Piracicaba (SINTICOMP) e as equipes da Estratégia Saúde da Família (ESF). Por meio destas equipes, seria possível identificar e priorizar o território de maior concentração de trabalhadores da construção civil, a ser selecionado para a realização do projeto piloto.

Foram contatadas as 25 equipes da ESF do município para que, através dos dados do Sistema de Informação da Atenção Básica (SIAB), se obtivesse o número de trabalhadores por região. O bairro escolhido foi o Tatuapé I, localizado na zona sul do município de Piracicaba-SP, com aproximadamente 1.0oo famílias cadastradas na área de abrangência da unidade de saúde, totalizando uma população de 3.80o habitantes e destes, $15 \%$, ou seja, 557 pessoas - são trabalhadores da construção civil. Para atender à população cadastrada, a equipe conta com uma médica, uma enfermeira, duas auxiliares de enfermagem e seis agentes comunitários de saúde.

Foram três reuniões preparatórias entre os profissionais da equipe da ESF, o representante do sindicato e a equipe de pesquisadores, para a apresentação e discussão do método escolhido e oitenta visitas nos domicílios, com as Agentes Comunitárias de Saúde (ACS), para levantar os dias favoráveis para a realização da ACT, explicar os objetivos do estudo e convidar os trabalhadores para a reunião. Como resultado, obteve-se contato direto com 33 trabalhadores, sendo que o contato maior foi com as esposas e filhos, pois eles estavam no trabalho. Além do convite verbal, foi deixado lembrete escrito, para cada domicílio ou trabalhador, que informava a data e o horário da reunião. A rádio comunitária do bairro produziu uma vinheta para lembrar o convite, nos dias que antecederam a ACT.

Apesar deste intenso trabalho preparatório, compareceram às duas reuniões de aplicação da ACT, sábado e domingo, no Centro Comunitário Municipal do bairro, apenas cinco trabalhadores, uma ACS, a médica da equipe de saúde, o representante do sindicato, além da equipe de pesquisadores.

Algumas explicações foram inferidas ao baixo comparecimento dos trabalhadores: (1) o setor da construção civil apresenta-se precarizado, itinerante, levando a jornadas de trabalho excessivas, inclusive nos finais de semana, restando muito pouco tempo livre aos trabalhadores; (2) a desorganização coletiva dos trabalhadores informais e a consequente descrença de que podem mudar a situação em que se encontram, levando-os a desconsiderar ou desconfiar das intenções do encontro; (3) a impossibilidade de contatar diretamente os trabalhadores, ficando a dúvida sobre a forma como os familiares transmitiram as informações a respeito dos objetivos do estudo.

Considerando as dificuldades acima e que o número de trabalhadores atendia às exigências da pesquisa qualitativa e do método da ACT, em especial, optou-se por analisar os dados coletados diante da riqueza dos achados e da sua consistência com a literatura.

As falas foram registradas em gravador analógico, transcritas e analisadas, segundo as categorias definidas pelo estudo. Além disso, as reuniões foram registradas em vídeo para auxiliar na transcrição. Na apresentação dos resultados, foram feitas pequenas edições para facilitar a leitura e compreensão.

Os participantes foram voluntários e participaram mediante assinatura do Termo de Consentimento Livre e Esclarecido. O estudo foi aprovado pelo Comitê de Ética em Pesquisa da UNIMEP Protocolo no: $53 / 08$.

\section{Resultados}

\section{Quem são os trabalhadores...}

Os trabalhadores que participaram da ACT são exclusivamente do sexo masculino, com idades que variaram de 31 e 60 anos, sendo que três exerciam a função de pedreiro e dois, de servente de pedreiro. 
Quanto à escolaridade, dois disseram ter $01^{-}{ }^{\circ}$ grau incompleto, dois não tiveram escolarização e um deles, de nacionalidade argentina, tinha $2^{\circ}$ grau completo, ingressou no Curso de Engenharia Eletrônica na Argentina, sem, contudo, concluí-lo. Trata-se, portanto, de uma história peculiar, deslocada do perfil comumente encontrado nesta categoria profissional.

A origem desses trabalhadores, com exceção do trabalhador estrangeiro, é rural, sendo que todos têm história de trabalho na lavoura de grãos, de cana-de-açúcar e de trabalho infantil. Um trabalhador relatou ter trabalhado como dinamitador em pedreira de calcário.

Nenhum dos trabalhadores entrevistados nasceu em Piracicaba, quatro migraram de outros Estados como Mato Grosso do Sul, Pernambuco, dois de Minas Gerais e um trabalhador imigrante da Argentina. Todos, entretanto, residem em Piracicaba há mais de 10 anos.

Os vínculos empregatícios desses trabalhadores são representativos da diversidade e precariedade de inserção desta categoria no mercado de trabalho: dois possuem registros como autônomos na Previdência Social, entretanto, o recolhimento ocorre somente nos meses em que eles estão contratados para a prestação de serviços em alguma obra, o que torna a contribuição previdenciária descontínua e circunstancial, com lacunas que certamente irão apresentar dificuldades futuras para o acesso a uma aposentadoria por tempo de serviço. Quanto aos demais, um está registrado numa grande empresa, outro trabalha sem registro por ainda não estar naturalizado em nosso país e o último está afastado em licença médica pelo INSS, recuperando-se de um acidente de trabalho.

\section{Como percebem seu contexto de trabalho...}

Desde as falas iniciais, os trabalhadores mostraram conviver em contextos de trabalho de desconfiança e desagregação, nos quais se estabelecem relações sociais de discriminação por parte dos contratantes, da sociedade em geral e até entre os próprios pares, o que é sentida por eles como desvalorização da profissão.
- "Pra entrar na obra é um sufoco, por causa da falta de confiança em nós (de quem contrata). E ele tem esse direito, porque quando ele contrata o cara ele conhece por fora não conhece por dentro... às vezes a pessoa que tá trabalhando ali não é uma pessoa direita (José4, pedreiro, 57 anos)".

A justificativa da desconfiança como um "direito" do contratante parece ser de tal forma aceita pelo trabalhador como uma contingência do seu contexto de trabalho que há uma naturalização da submissão a situações que colocam em risco a sua própria vida:

- "A pessoa tem que ser de confiança, igual uma empregada, como a senhora vai deixar a chave comigo sem confiança? Uma vez nós tava trabalhando na reforma (de um edifício), arrancando todas as ripas, descendo a laje, de andar em andar, aí chegou no quarto andar a mulher falou: "No meu apartamento, de jeito nenhum, ninguém entra não"! Aí então tive que subir uns quatro ou cinco andares pela corda, eles me puxando pela carretilha, por fora do prédio. Sabe que depois nesta noite eu até sonhei com isto! (Antonio, pedreiro, 52 anos)".

$\mathrm{Na}$ fala a seguir, ficam implícitas também as relações de poder envolvidas quando o saber prático operário entra em conflito com o saber reconhecido e valorizado dos especialistas:

- "Às vezes a gente entra em contradição com o engenheiro, porque ele dá as medidas, mas o terreno não é compatível com as medidas que ele dá... Aítem que entrar em contato com o engenheiro e trazer ele na obra, às vezes você encontra um casca dura que num tem jeito (Danilo, pedreiro argentino, 38 anos)."

Decorrente dessa assimetria, os trabalhadores convivem com um sistema de trabalho fortemente hierarquizado, de relações sociais de dominação entre as categorias profissionais:

- "Nós somos os pedreiros e os ajudantes (serventes) já sabem a nossa norma de trabalhar, o material que vamos precisar usar ali. Eu chego pro ajudante e digo, você vai fazer uma massa, coloca dois carrinhos de areia, um saco de cal e uma lata de cimento.... pedreiro como ele é profissional ...ele

4 Os nomes utilizados são fictícios para preservar o anonimato dos trabalhadores. 
não quer saber de pegar a lata de areia ou a lata de massa pra levar no caixote... Ele fica ali esperando... Se ficar o dia todo sem aparecer o material no pé dele, ele fica o dia inteiro sem trabalhar..." (José, pedreiro).

A justificativa para diferenças salariais entre pedreiros e ajudantes sustentar-se-ia em que a maior responsabilidade do pedreiro no trabalho implica em exigências de ordem mais cognitiva, o que estabelece uma diferenciação com o trabalho do ajudante, que é uma atividade braçal.

- "Eu num faço diferença entre o pedreiro e o ajudante, pra mim tem o mesmo valor (social) (grifo nosso)... Porque se o pedreiro ganha mais é porque ele tem mais responsabilidade, só que o serviço dele é mais leve do que o serviço do ajudante, então o ajudante ganha menos porque a responsabilidade é menos, mas o serviço é mais pesado. Então eu me comparo igual a eles (os ajudantes) (José, pedreiro)".

A maior facilidade de absorção de mão de obra pelo setor da construção civil possibilita trajetórias como a do pedreiro argentino, mostrando os efeitos da reestruturação produtiva capitalista nos países periféricos. A história do trabalhador estrangeiro, ainda que singular, agrega-se ao conjunto pelo seu ingresso na construção civil como um caminho possível no enfrentamento do desemprego e exclusão social, gerados pelos modelos de ajuste econômico:

- "A firma foi à falência, aí eu num tive condições de pagar meus estudos, e tive que parar. Na época ficou difícil também porque as firmas estavam mandando o pessoal embora pra por robô trabalhando no lugar de pessoas. Hoje o sistema lá é tudo automatizado. Aí começaram a colocarmaquinário no lugar de pessoas, ficou difícil. Aí o trabalho na construção civil...” (Danilo, pedreiro argentino)

- "A gente trabalha numa área, num serviço, que é a única opção que a gente tem porque é uma profissão, uma área de serviço que num tem valor, por isso mais fácil de ingressar, (complemento nosso) pra falar a verdade não tem valor nenhum" (Pedro, servente, 53 anos).

As histórias de trabalho infantil na construção civil foram recorrentes, mostrando a aceitação e a insatisfação de uma hereditariedade social determinista:

- "Não gosto muito da profissão, eu cresci nessa profissão desde os oito anos aguentando cascudo na orelha do meu padrasto, aí aprendi... (Danilo, pedreiro argentino)."

- "Essa profissão aí vem de família, trabalhei desde criança com meu pai e nunca gostei" (Pedro, servente).

Na percepção dos trabalhadores, a construção civil é um setor no qual existe pouca mobilidade profissional, como por exemplo, a ascensão profissional de pedreiro a mestre de obras, vista como uma situação que acontece raramente e por isto percebida como privilégio de alguns:

- "Tem mestre de obra que sai de ser pedreiro para ser mestre de obra, só que para ele passar a mestre tem que fazer um curso... tempos atrás eu ia fazer, mas ficava uns $R S$ 200,oo, agora ta uns $R S 350,00$. Agora tem alguns pedreiros que vai pegando bastante conhecimento na firma, e ele tem sabedoria,é bem inteligente, aí ele vai passando a encarregado, vai subindo, vão vendo a capacidade dele, ele passa a carta dele pra mestre de obra sem ter o curso. Tem pessoas que têm esse privilégio" (José, pedreiro).

Duas situações foram enfatizadas: na primeira a ascensão profissional é vista como um mérito de competência, mas é tida como algo complicado e que dificilmente acontece, e na segunda, de maior frequência, a ascensão está condicionada a indicações que não necessariamente estão relacionadas com conhecimento e experiência:

- "O mestre de obras às vezes é um pedreiro que tem bastante experiência e virou mestre de obras, mas, às vezes é um que não entende "patavina" e só dá dor de cabeça pra gente. É complicado chegar a mestre de obra nas firmas porque a maioria põe alguém conhecido" (Danilo, pedreiro argentino).

\section{Como os trabalhadores entendem sua atividade $e$ sua carga de trabalho...}

As falas dos trabalhadores mostraram vários indícios da sobrecarga musculoesquelética à qual estão expostos em diversas regiões do corpo, mas, 
preferencialmente nos ombros, coluna e joelhos. Os constrangimentos são maiores ou menores dependendo das condições de trabalho e meios disponíveis para a realização das tarefas:

- "Vamos supor um reboque. Então chego lá e falo pro ajudante, você vai fazer uma massa que se coloca aí dois carrinhos de areia, um saco de cal e uma lata de cimento... Com a pá põe na carriola, aí quando não tem carriola, já pega na lata. São latas de vinte litros. Enche a lata põem no ombro, agora conforme a distância ele já carrega rapidinho na mão mesmo..." (José, pedreiro).

0 trabalho é pesado, exige esforço e carregamento de peso, gerando sobrecarga nas vértebras e discos intervertebrais:

- "Isso aí pode trazer um problema pra coluna, por causa da força que faz de puxar com a enxada... É... esforça bastante principalmente a coluna. Para misturar areia com o cimento é difícil. Trabalha muito abaixado, força muito" (José, pedreiro).

- "Você tem que trabalhar assim aqui (levanta-se e faz movimentos demonstrativos) então, quando você levanta, você fala "ai minha coluna”! (Pedro, servente).

- "Vamos supor que a gente tá medindo na lata, seis latas de areia, um saco de cal e uma lata de cimento. $O$ saco de cal tem 20 quilos, o de cimento 25 quilos..." (José, pedreiro)

- [...]“Eu ponho a lata no ombro e subo a escada segurando"... (Pedro, servente).

Para a realização das tarefas, a manutenção de posturas estáticas, a repetitividade, a vibração e a sobrecarga musculoesquelética ficam evidenciadas:

- "Bate a colher assim", demonstrando um movimento (Mariano, servente).

- "Pra fazer o reboque nessa parede aqui é de baixo pra cima aí eu bato, porque aí eu bato a massa até altura que eu alcanço, é mais fácil até de aprumar ela, aí eu faço a parte de baixo (na parte mais baixa na posição agachado) e depois eu jogo o andaime e subo" (José, pedreiro).

- "Sarrafiar a massa, é você batê a massa na parede, ai ela fica tudo assim "chapiscada" aí depois pra corrigir isso aí passa o sarrafo, e depois vem a desempenadeira, que vai alisar a massa" (Danilo, pedreiro argentino).

- "Na maioria dos pedreiros... a gente trabalha ajoelhado em cima da massa tudo molhada, úmida, sempre tem isso aqui... o joelho fica tudo esfolado, pega até a friagem no joelho. Quando é no piso, o pedreiro puxa com a enxada e sarrafeia. Aí num dá pra ser ajoelhado, é de "cocado", de cócoras, (complemento nosso) (José, pedreiro).

- "É muito difícil obra que usa o soquete, tem uma máquina que se chama o sapo, que é pra você sapiar a terra, socar ela (Mariano, servente). $O$ soquete não dá resultado nenhum... (Danilo, pedreiro argentido). Só acaba com os braços" (Pedro, servente).

Apesar de gostarem do trabalho, os relatos demonstram que os trabalhadores têm plena consciência do trabalho pesado ao qual se sujeitam:

- "Eu gosto de trabalhar. É a parte que eu mais adoro é trabalharna construção civil. É um serviço prático e é um serviço ali tudo você sabe fazer.

Mas, eu num gosto de abrir valeta. Falou de abrir alicerce eu num gosto. Porque é um serviço pesado. Outra coisa, num gosto de aterrar obra, é serviço pesado, é bruto, Deus me livre. Dói muito o corpo. Deus me livre! Arrebenta, acaba com a gente"... (Pedro, servente).

\section{Como os trabalhadores percebem e enfrentam os riscos no trabalho...}

As dificuldades com o uso dos Equipamentos de Proteção Individual (EPIs) estiveram presentes nos depoimentos:

- "Incomoda pra trabalhar, às vezes você está com muita coisa de segurança e num dá pra trabalhar direito. O que mais incomoda na parte que eu trabalho é a luva de couro, eu tenho alergia aqui (mostra a mão), o protetor (auricular) não incomoda, o capacete, esquenta tudo a cabeça aqui, esquenta muito, é muito quente" (Mariano, servente).

O trabalho em alturas é uma preocupação para os trabalhadores, eles mostram saber dos riscos que correm por trabalharem nessa condição, porém, os sistemas de proteção, por um lado são apontados como eficazes e por outro, dificultam o desempenho das atividades: 
- "A corda está amarrada, então se a pessoa escapar ele tá laçado na corda, a corda está amarrada na ponta do andaime lá e na outra ponta de cá, então ele tá lançado ali e se por acaso ele escapar ele fica pendurado. (Pedro, servente)."

- "De toda a segurança, de todos os equipamentos o que mais incomoda a gente é o cinto." "É... você está andando ele trava (enrosca) aí você tem que voltar pra trás e desenroscar " (Danilo, pedreiro argentino).

O uso dos EPIs foi apontado como uma exigência da empresa e não como uma necessidade da atividade, demonstrando que existe uma percepção de autocontrole do risco:

- "Tudo isto aí (usar equipamentos de segurança) depende das exigências da firma, se for um empreiteiro ele não está nem aí, mas se o proprietário (contratante) é engenheiro, aí tem que usar. Eu tenho muito costume de altura, não tenho medo de nada, mas tem firma que não aceita, e este é o certo, pra trabalhar em lugar alto, acima de dois metros de altura tem que usar o cinto. Se for exigência da firma a gente vai usar, mas acontece que estou acostumado (foi eliminada a sensação de risco), todo mundo já está naquele ritmo (aquecido pela atividade)... (grifos nossos) (Mariano, servente).

- Se você está numa obra que não tem essa exigência, você vai exigir de sua parte? Os seus colegas de trabalho vão pegar pra cima de você... vão tirar sarro... vão falar que você é puxa saco do patrão, é isso e aquilo, a favor do patrão" (grifos nossos) (José, pedreiro).

Como fala discordante, um trabalhador discorreu sobre outro sistema de proteção $0^{5}$ para trabalho em altura, usado por ele, considerado mais eficaz e que não atrapalha:

- "Dá pra fazer também outra coisa na parte de cima, aí eu furei a parede e fiz um tipo uma barrigada, um sobrado ali, então não tem como cair, porque os lados têm ... tipo uma gradinha de proteção... A segurança minha aí é o corrimão, eu não uso cinto de segurança, você vai cair, o corrimão protege" (Danilo, pedreiro argentino).
Diante da ineficácia total dos equipamentos de proteção individual e das dificuldades de fazer o trabalho prescrito no trabalho real, os trabalhadores desenvolvem modos próprios de fazerem o trabalho e de enfrentarem riscos.

\section{Discussão}

Foram pressupostos deste trabalho que a saúde e a doença representam uma complexa interação entre aspectos físicos, psicológicos, sociais e ambientais da condição humana e que as condições de vida e de trabalho qualificam de forma diferenciada a maneira pela qual pensam, sentem e agem as classes sociais e seus segmentos (Minayo, 1998).

Os estudos de Oliveira e Iriart (2008) e de Santana e Oliveira (2004) expressam o seguinte perfil sociodemográfico da população empregada na construção civil: majoritariamente do sexo masculino, migrantes, originários da zona rural, com baixa escolaridade, reduzida qualificação profissional e baixa cobertura previdenciária devido à temporalidade e inconstância dos vínculos empregatícios formais. Consoante com esses dados, os trabalhadores que aceitaram participar deste estudo apresentaram perfil semelhante.

Os achados confirmaram os aspectos objetivos da carga de trabalho e dos fatores de risco: (1) trabalho predominantemente manual com excessiva exigência de esforço físico, com carga estática e movimentos repetitivos; (2) o trabalho em altura, em condições improvisadas e perigosas; (3) a exposição às intempéries, ruídos dos equipamentos, poeira, dentre outros. Esses fatores estão reconhecidamente presentes na construção civil e afetam a saúde e a segurança dos trabalhadores. Entretanto, foram detectados outros aspectos nocivos, de natureza subjetiva e social, que precisam ser considerados na aplicação de ações educativas preventivas com os trabalhadores.

Conforme observado empiricamente pelos pesquisadores deste estudo, a convivência com a temporalidade - alternância de emprego e desemprego - e com vínculos precários de trabalho - trabalho informal, alta rotatividade, achatamento salarial -

5 Trata-se do sistema de proteção coletiva tipo guarda corpo (Normas Regulamentadoras nº 18 - Ministério do Trabalho e Emprego). 
parece explicar a naturalização das atitudes sociais de estigma, discriminação e até mesmo exclusão, identificadas nas narrativas dos trabalhadores, apresentadas nos resultados deste estudo. Da mesma forma, os acidentes e as doenças são vistos pelos sujeitos estudados como eventos normais esperados e inerentes ao próprio trabalho.

A fragmentação do processo produtivo na construção civil dificulta a identificação dos trabalhadores como categoria, repercute em índices baixos de sindicalização, afetando a combatividade das entidades sindicais, favorecendo a permanência das relações encontradas. Os trabalhadores evidenciam a consciência da sua invisibilidade social, jurídica, política e também moral, refletindo na própria consideração do valor pessoal e de seus pares (Oliveira e Iriart, 2008).

Outro lado da mesma moeda é a desvalorização profissional. De raiz ideológica e cultural, a não valorização do saber operário é o ideário de sustentação da divisão social do trabalho, baseada nas noções dos trabalhadores que pensam e por isso têm um saber reconhecido e os trabalhadores que fazem e por isso estariam desprovidos de saber. As ocupações da construção civil são ofícios que, na maior parte das vezes, são aprendidos pelo viés prático, não demandando, no ingresso, qualificação e treinamento, o que, por um lado, representa maiores possibilidades de inserção profissional, mas por outro, contribui para o não reconhecimento social da categoria (Oliveira e Iriart, 2008).

Na construção civil, os perigos têm um peso real e muitos operários testemunharam acidentes fatais ou que resultaram em invalidez dos acidentados. Como nos diz Dejours (1998), esses perigos têm o potencial de se personalizarem a qualquer momento, no decorrer das atividades: um passo em falso e o operário cai do andaime!

Diferentemente do pensamento hegemônico (Gramsci, 1995), os operários estão conscientes dos riscos, pois se trata de um aprendizado diário do que é seguro ou não nas obras que ajudam a construir. $\mathrm{Na}$ pesquisa realizada por Iriart e colaboradores (2008), esse conhecimento está muito presente na identificação de acidentes tais como, tijolos e outros materiais que caem e podem atingi-los, carregar peso excessivo, contato com substâncias tóxicas e objetos perfurantes, além do risco de queda.

No entanto, os operários sabem também que os riscos não são eliminados totalmente pela gestão da organização do trabalho e que a utilização do EPI não tem grande eficácia na prevenção dos acidentes, sua função é apenas de minimizar, em alguns casos, a gravidade do acidente. Essa insuficiência faz com que os riscos sejam assumidos individual e coletivamente pelos trabalhadores.

Medeiros e Rodrigues (2002) observaram que os trabalhadores da construção civil desenvolvem uma série de medidas de precaução para evitar acidentes e doenças relacionadas ao trabalho, a partir de seu próprio saber, usando modos de agir que, ainda que de forma temporária, apresentam-se como soluções às situações arriscadas que enfrentam no trabalho. Foi realizado um inventário dessas soluções que não foram instruídas pelos manuais de Segurança do Trabalho, mas que foram desenvolvidas como parte de um conhecimento que não está escrito, que não se formaliza, mas que circula entre os trabalhadores, transmitido de forma oral ou simplesmente visual (pela observação). Elas foram percebidas em contextos de trabalho menos autoritários e com sentimentos de cooperação e companheirismo (Medeiros e Rodrigues, 2002).

No entanto, apesar de novos olhares, surgidos principalmente a partir de estudos ergonômicos voltados para as atividades de trabalho ${ }^{6}$, os trabalhadores da construção civil são tradicionalmente apontados como pertencentes a uma categoria profissional resistente às normas de segurança e com um alto índice de aversão ao uso de EPIs.

Neste estudo, detectaram-se conteúdos diferenciados nas falas dos trabalhadores em relação aos EPIs: a referência ao uso propriamente dito dos equipamentos, ao desconforto que eles provocam no trabalhador e como, muitas vezes, eles atrapalham na condução das tarefas, principalmente diante da intensificação do trabalho e das exigências de perfeição e cumprimento de prazos, ou seja, da

6 Em especial os estudos que utilizam da metodologia denominada AET (Análise Ergonômica do Trabalho). Ver Guerin e colaboradores, 2001. 
pressão por qualidade e produtividade, características fortemente marcadas no mercado de trabalho capitalista competitivo. Aos efeitos psicossociais desses constrangimentos, aliam-se a fragilidade dos vínculos que tangenciam as atitudes de adaptação e submissão; os conteúdos de causas intersubjetivas que expressam os modos de regulação dos operários diante da necessidade de lidar com os riscos.

As falas dos operários exemplificam as ideologias defensivas (Dejours, 1992) para conter e ocultar a ansiedade por desenvolver uma atividade percebida como perigosa, seja pela negação do perigo e a crença do controle pelo costume, seja pela experiência e o saber prático que dela decorre.

Nos estudos do autor, esta percepção é apontada como um sistema defensivo partilhado entre todas as categorias profissionais da construção civil, cuja eficácia simbólica é assegurada pela participação coletiva. Por se tratar de uma ideologia defensiva de profissão, torna-se incontestável seu valor funcional e aquele trabalhador que não conseguir incorporá-la no trabalho será alvo de "gozações" de seus colegas, principalmente as relacionadas com virilidade e coragem.

Segundo os estudos de Llory (1999), os operadores desenvolvem não só competências "técnicas", mas também um conjunto de competências relativas ao trabalho coletivo e à vida social no meio em que trabalha. Trata-se do saber fazer de ofício, um modo peculiar que os coletivos adotam, uma forma de inteligência astuciosa não formalizável.

$\mathrm{O}$ autor ainda recomenda aos profissionais de segurança e aos gestores que prestem atenção na escola do "chão de fábrica”, na prática do trabalho, organizando debates abertos sobre os riscos, as dificuldades organizacionais e os fracassos do trabalho, no sentido de perceber e desenvolver as capacidades e compreender as contracapacidades - os pontos fracos e vulneráveis.

Dejours (1998) identificou atitudes de negação do risco, que não devem ser confundidas com as atitudes de regulação ergonômica, uma vez que as primeiras representam uma ocultação da vivência cotidiana do medo, que se encontra contida por mecanismos de defesa, e que têm a função psicológica de neutralizar esta emoção para preservar a saúde mental dos trabalhadores. Estes mecanismos de de- fesa são de caráter coletivo e sua eficácia simbólica depende da aceitação e participação de todos. Se assim não fosse, se o medo aparecesse a toda hora durante o trabalho, os trabalhadores certamente não conseguiriam continuar em suas tarefas por muito mais tempo.

Athayde (1996) reforça a importância de se considerar a ideologia defensiva nas ações educativas com trabalhadores, respeitando-se os mecanismos psíquicos defensivos, pois, combater de frente tais defesas pode resultar em diversos efeitos negativos, tornando-lhes as tarefas ainda mais difíceis de serem executadas, e dessa forma, o trabalho mais carregado de ansiedade.

\section{Considerações Finais}

Vilela (2003), analisando a política de prevenção de acidentes de trabalho no Brasil, refletida no material educativo produzido para as campanhas de prevenção como cartazes e cartilhas, mostra que há o objetivo de adaptar o trabalhador aos riscos existentes, vistos como inerentes ao processo produtivo, bem como uma evidente transferência de responsabilidade das empresas aos trabalhadores. A organização transfere ao trabalhador a tarefa de gestar individualmente o risco "evitando" o acidente, enredado por uma ideologia que leva a sua autoculpabilização quando este ocorre. Trata-se da visão do acidente como "ato inseguro" do trabalhador, efetuada pelos profissionais de Segurança do Trabalho na conscientização e adequação do comportamento do trabalhador.

Em contraposição a esta visão dominante, Almeida e Jackson Filho (2007) referem que novas concepções acerca dos acidentes estão ganhando força por parte de estudiosos do tema e, em consequência, novos modelos de análise vêm sendo desenvolvidos, buscando identificar, na complexidade desses eventos, os fatores sociotécnicos que os desencadeiam e, simultaneamente, as condições preexistentes no trabalho sem as quais os acidentes não ocorreriam.

Para que este novo conteúdo paradigmático estabeleça a ruptura desejada, é preciso que ele seja compartilhado com os trabalhadores, com o corpo técnico das empresas, com as instâncias pú- 
blicas de regulação e com as entidades sindicais, transformando-se em fundamentos mais efetivos na construção de consensos e compromissos destes diferentes atores sociais na construção de uma efetiva política pública de prevenção dos acidentes de trabalho.

A formação de agentes multiplicadores é uma das estratégias desenvolvidas pelo CEREST-Piracicaba nesta direção, porém as características da construção civil indicam que a formação desejada deve ser norteada por uma pedagogia transformadora - diferente daquela que apenas transmite conhecimentos - que permita potencializar o saber operário e articulá-lo com outros saberes de modo que os trabalhadores tornem-se sujeitos na elaboração e uso do material educativo (Freire, 2007). Além disso, as medidas educativas devem alcançar toda a sociedade, de modo que a atividade de trabalho da construção civil ganhe visibilidade, seja igualmente compreendida por quem demanda a construção, empreita a obra e contrata os trabalhadores.

\section{Agradecimentos}

A Ecléa Spiridião Bravo, Carmem Aparecida Herrera Gonçalves e Milton Costa pela colaboração na pesquisa de campo.

\section{Referências}

ALMEIDA, I. M.; JACKSON FILHO, J. M. Acidentes e sua prevenção. Revista Brasileira de Saúde Ocupacional, São Paulo, v. 32, n. 115, p. 7-18, 2007.

ASSUNÇÃO, A. A.; LIMA, F. P. A. A contribuição da ergonomia para a identificação, redução e eliminação da nocividade do trabalho. In: MENDES, R. (Org.). Patologia do trabalho. 2. ed. São Paulo: Atheneu, 2003.

ATHAYDE, M. R. C. Psicodinâmica do trabalho: gestão de coletivos de trabalho e modernidade, questões para a Engenharia de Produção. 1996. Tese (Doutorado em Engenharia de Produção) - Faculdade de Engenharia de Produção da Universidade Federal do Rio de Janeiro, Rio de Janeiro, 1996.

BERLINGUER, G. A saúde nas fábricas. São Paulo: Hucitec, 1983.
BRASIL. Ministério da Previdência Social. Anuário estatístico da Previdência Social, 2007. Brasília, DF, 2007. Disponível em: <http://www. mpas.gov.br/conteudoDinamico.php?id=423>. Acesso em: 22 nov. 2012.

DEJOURS, C. A loucura do trabalho: estudo da psicopatologia do trabalho. São Paulo: Cortez Oboré, 1992.

DEJOURS, C. A banalização da injustiça social. Rio de Janeiro: FGV, 1999.

DIEESE - DEPARTAMENTO INTERSINDICAL DE ESTATÍSTICA E ESTUDOS SÓCIO-ECONÔMICOS. Os trabalhadores e a reestruturação produtiva na construção civil. São Paulo, 2001. (Estudos Setoriais, 12). Disponível em: <www.dieese.org.br/ esp/civil.pdf >. Acesso em: 22 nov. 2012.

DIEESE - DEPARTAMENTO INTERSINDICAL DE ESTATÍSTICA E ESTUDOS SÓCIO-ECONÔMICOS. O trabalho por conta própria na construção civil. Boletim Trabalho e Construção, São Paulo, n. 5, fev. 2011. Disponível em: <http://www.dieese.org. br/esp/boletimConstrucaoCivil5_fev2011.pdf>. Acesso em: 22 nov. 2012.

FERREIRA, L. L. Análise coletiva do trabalho. Revista Brasileira de Saúde Ocupacional, São Paulo, v. 21, n. 78, p. 7-19, 1993.

FREIRE, P. Pedagogia do oprimido. 46. ed. Rio de Janeiro: Paz e Terra, 2007.

GRAMSCI, A. A concepção dialética da história. 10. ed. Rio de Janeiro: Civilização Brasileira, 1995.

IRIART, J. A. B. et al. Representações do trabalho informal e dos riscos à saúde entre trabalhadoras domésticas e trabalhadores da construção civil. Ciência \& Saúde Coletiva, Rio de Janeiro, v. 13, n. 1, p. 165-174, 2008.

LLORY, M. Acidentes industriais: o custo do silêncio. Rio de Janeiro: Multimais, 1999.

MEDEIROS, J. A. D.; RODRIGUES, C. L. P. A existência de riscos na indústria da construção civil e sua relação com o saber operário. In: ENCONTRO NACIONAL DE ENGENHARIA DE PRODUÇÃO, 21., 2001, Salvador. Anais... Salvador: ABEPRO, 2001. 1 CD-ROM. 
MINAYO, M. C. S. O desafio do conhecimento: pesquisa qualitativa em saúde. São Paulo: Hucitec; Rio de Janeiro: Abrasco, 1996.

OLIVEIRA, R. P. “Tudo é arriscado”: a representação do trabalho entre trabalhadores informais da construção civil. 2004. Dissertação (Mestrado em Saúde Coletiva) - Universidade Federal da Bahia, Salvador, 2004.

OLIVEIRA, R. P.; IRIART, J. A. B. Representações do trabalho entre trabalhadores informais da construção civil. Psicologia em Estudo, Curitiba, v. 13, n. 3, p. 437-445, 2008.

SANTANA, V. S.; OLIVEIRA, R. P. Saúde e trabalho na construção civil em uma área urbana do Brasil. Cadernos de Saúde Pública, Rio de Janeiro, v. 2o, n. 3, p. 797-811, 2004.

TOMÁS, E. A. Entre la precariedad laboral y la exclusión social. In: TOMÀS, E. A.; BERNAL, A. O. Trabajo, indivíduo y sociedad: perspectivas psicosociológicas sobre el futuro del trabajo. Madrid: Pírámide, 2001. p. 95-144.

VILELA, R. A. G. Desafios da vigilância e da prevenção de acidentes do trabalho. São Paulo: LTr, 2003. 